\title{
SERÁ LIVRO?
}

\section{Daiane Carneiro Pimentel*}

RESUMO: Proponho-me a desenvolver uma leitura de Serafim Ponte Grande, de Oswald de Andrade, a fim de demonstrar que em tal obra a dimensão crítica pode ser verificada na problematização das noções de escrita, de romance e de livro. A princípio, serão abordados o modo como Serafim relaciona-se com a escrita e o fato de o protagonista planejar compor um romance. Em seguida, será analisada a unidade intitulada "O Merediano de Greenwich", um "romance de capa e pistola" que, por meio da paródia, desconstrói práticas literárias e atinge material e textualmente a cultura livresca. Serafim Ponte Grande constitui-se, tuscim, como uma obra que tensiona seus próprios limites eque assim, como u obra que Sension seus propilos limites eque solicita de seu leitor uma postura interpretativa também pautada pela negatividade, isto é, pela recusa dos lugares-comuns da investigação crítica. Ao desdobrar a negatividade de Serafim Ponte Grande, pretendo explicitar elementos que fazem desta produção oswaldiana um não-livro.

PALAVRAS-CHAVE: não-livro; paródia; Oswald de Andrade.
* d.cpimentel@yahoo.com.br

Doutoranda em Estudos Literários pela Faculdade de Letras da

Universidade Federal de Minas Gerais. Bolsista da CAPES.

RÉSUMÉ: Je me propose de développer une lecture de Serafim Ponte Grande, de Oswald de Andrade, afin de démontrer que dans cette œuvre la dimension critique peut être verifiée dans la problématisation des notions d'écriture, de roman et de livre. Au début, seront abordés la manière dont Serafim se met en rapport avec l'écriture et le projet de celui-ici de composer un roman. Ensuite, sera analyser l'unitée intitulée "O Merediano de Greenwich", un "roman de cape et de pistolet" qui, à travers la parodie, déconstruit des pratiques littéraires et atteint matériellement et textuellement la culture livresque. Serafim Ponte Grande ches limites et qui sollicite à son locteur une posture ines propes limites et qui sollicite à son lecteur une posture interpretative aussi guidée par la négativité, c'est à dire, par le refus des notions conventionnelles de l'investigation critique. En dédoublan la négativité de Serafim Ponte Grande, je vise à démontrer des éléments qui font de cette production oswaldienne un non-livre.

MOTS CLÉS: non-livre; parodie; Oswald de Andrade. 
Toda invenção é uma crítica Toda crítica é invenção

Michel Butor

\section{ESCREVER - E LER - PELO NÃO}

Em um ensaio em que a reflexão sobre a literatura foge aos padrões acadêmicos mais rígidos e constrói-se a partir de produtivas imagens poéticas, Michel Butor ${ }^{1}$ argumenta que a invenção literária realiza uma crítica, assim como o trabalho da crítica envolve a invenção. Guiada por essa ideia defendida por Butor, proponho-me a desenvolver uma leitura de Serafim Ponte Grande, de Oswald de Andrade, a fim de demonstrar que em tal obra a dimensão crítica pode ser verificada na problematização das noções de escrita, de romance e de livro. Trata-se, pois, de uma obra autorreflexiva, uma obra que tensiona seus próprios limites e que solicita de seu leitor uma postura interpretativa também pautada pela negatividade, isto é, pela recusa dos lugares-comuns da investigação crítica. Como sugere Butor: "A obra nova é um germe que cresce no terreno da leitura; a crítica é como sua floração". ${ }^{2}$

A negatividade de Serafim Ponte Grande repercute - floresce, segundo a terminologia empregada por Butor - em "Serafim: um grande não-livro", artigo no qual Haroldo de Campos retoma e subverte o modo como Antonio Candido, em "Estouro e libertação", havia caracterizado esse romance oswaldiano. Serafim Ponte Grande é, para Candido, um "fragmento de grande livro"; já para Campos, é um "grande não-livro de fragmentos de livro". A Ambos os autores destacam a fragmentação da obra, fragmentação essa que ocorre em diversos planos e advém do emprego de uma série de recursos, tais como: a sintaxe metonímica, a divisão da narrativa em unidades bastante desconexas entre $\mathrm{si}^{5}{ }^{5} \mathrm{o}$ desrespeito à cronologia e a incorporação de vários gêneros textuais. ${ }^{6}$ Entretanto, diante da atestada fragmentação, a perspectiva crítica adotada por cada um dos autores é distinta: na reformulação proposta por Campos, introduz-se a expressão "não-livro" e, por conseguinte, abandona-se certa valorização do objeto livro, a qual envolveria uma abordagem restritiva da técnica empregada por Oswald. ${ }^{7}$

A análise de Serafim Ponte Grande empreendida por Campos é retomada por Flora Süssekind em "Não-livros", ensaio dedicado a produções de escritores e de artistas visuais as quais, por meio de variados mecanismos, inserem-se na cultura livresca ao mesmo tempo que a negam. Nota-se, portanto, que Süssekind explora as potencialidades da expressão "não-livro" e emprega-a de modo mais abrangente do que Campos. A pesquisadora ressalta que as ideias de linearidade, legibilidade e finitude são costumeiramente atribuídas ao "livro", 8 que deve considerado não apenas como um objeto físico, mas 
também como texto e técnica editorial. Sob a perspectiva de Süssekind, o conceito de "não-livro" abarcaria tanto obras cuja negatividade manifesta-se na própria materialidade graças à utilização de suportes inovadores (sobretudo os dos meios digitais), à desfiguração do registro verbal e/ou do visual e ao desmonte da forma-livro convencional - quanto obras que tensionam "de dentro" a cultura livresca - graças a uma autoexposição crítica que, abrangendo o processo de escrita e o de recepção, atinge as figuras do autor e do leitor, bem como as práticas que constituem a "vida literária" de determinada sociedade. Os dois grupos de "não-livro" acima delineados não são excludentes; pelo contrário, todos os mecanismos elencados podem estar combinados em uma só obra, como demonstra a referida pesquisadora a partir da análise dos trabalhos dos escritores Zuca Sardana, Valêncio Xavier e Sebastião Nunes.

Süssekind também identifica em Serafim Ponte Grande "um duplo movimento - textual e material - de autodesnudamento e desarticulação tanto da forma romanesca quanto da forma-livro". ${ }^{9}$ Contudo, é digno de nota que, diferentemente de Zuca Sardana, Valêncio Xavier e Sebastião Nunes, Oswald de Andrade não realiza, em Serafim Ponte Grande, grandes inovações no que diz respeito ao suporte, à plasticidade das palavras e ao formato do livro nem incorpora desenhos ou outras imagens à narrativa. Quanto ao aspecto material, é possível dizer que, no romance oswaldiano em questão, a visualidade das páginas e da escrita ganha algum relevo, devido à exploração criativa dos espaços em branco e da utilização do itálico e da caixa-alta. A dimensão visual inclusive ajuda a delimitar os muitos gêneros textuais inseridos em Serafim Ponte Grande (Figuras 1 e 2). Ademais, conforme Campos já salientara, tal obra contesta sistematicamente certas convenções caras à literatura impressa:

A contestação do livro, como objeto bem caracterizado dentro de um passado literário codificado e de seus ritos culturais, começa aqui, desde logo, pela materialidade, pela fisicalidade desse objeto. No lugar onde costumeiramente se indicam as "Obras do Autor", a relação destas vem sob a rubrica "Obras Renegadas", e o próprio livro que se está para 1er, o Serafim Ponte Grande, é incluído entre os títulos "repudiados". A indicação de copyright - chancela dos direitos do autor e da propriedade literária - é parafraseada em tom escarninho ("Direito de ser traduzido, reproduzido e deformado em todas as línguas"). Há uma "Errata", deslocada de sua posição habitual, que funciona autonomamente, como se fora um capítulo. Finalmente, o que corresponderia a um cólofon (indicação da data da elaboração do livro) é também submetido a um tratamento inusitado: a cronologia é posta ao revés, como se vista pelas lentes distanciadoras de um binóculo focalizado ao contrário: "Este livro foi escrito de 1929 (era de Wall-Stret e Cristo) para trás" [...]. ${ }^{10}$ 
Mas a força da negatividade de Serafim Ponte Grande não advém somente nem principalmente do questionamento da materialidade do objeto livro. Corrobora tal perspectiva o fato de as páginas do romance, mesmo recebendo gêneros textuais de origem diversa, apresentarem uma homogeneidade tipográfica, a qual é quebrada apenas quando se faz uso do itálico, da caixa-alta ou dos espaços em branco. Entendo que o movimento textual - e não o material - é predominante em Serafim Ponte Grande, cujo tensionamento da cultura livresca ocorreria, então, sobretudo "de dentro", uma vez que, como sugeri acima, tal obra não rompe de modo radical com o suporte, o registro verbal e a forma do objeto livro.

Com base em Süssekind, pretendo demonstrar que esse romance oswaldiano realiza uma "espécie de catálogo crítico da prosa convencional" e uma "intervenção e alteração de modelos literários e práticas textuais". ${ }^{11}$ A princípio, abordarei o modo como o protagonista Serafim relaciona-se com a escrita. Neste momento, discutirei o fato de o protagonista planejar compor um romance. Em seguida, e à luz da primeira parte da minha análise, enfocarei o "romance de capa e pistola" intitulado "O Merediano ${ }^{12}$ de Greenwich", o qual compõe a sétima unidade de Serafim Ponte Grande. $\mathrm{Na}$ esteira de Süssekind, é possível dizer que os aspectos por mim enfatizados provocam uma desarticulação dos modelos investigativos empregados pela crítica literária e emprestam

Abaixo-assinado

por alma de Benedito Carlindoga

Destinado à elevaçăo de uma herma a ésse venhor

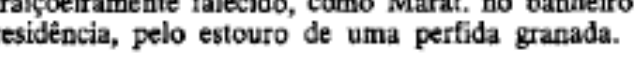

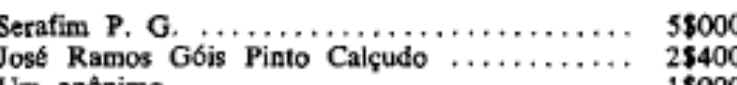


D

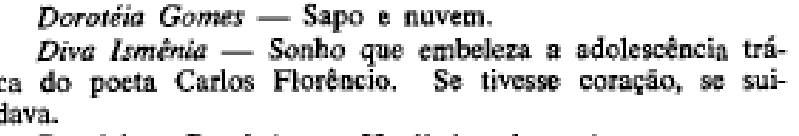
ga do poeta Carlos Florêncio. Se tivesse coraçâo, se sui-

Domiciano Bombeiro - Herói das chom

Seu Eligênio - Marido da Gija Mme. Firmina - Estréla de primeira grandeza da Com-
panhia de Operas e Operetas Salvaterra. Pernas diguas de
museu!

Dona Guiomar - Senhora importante da sociedade. Co-
hecoo-a de ouvido.

Helena - Filha de Seu Hipólito.
Henriqueta - Irmă da precedente.

Henriquecta - Trmá da prectito - Pai das duas.

Inácio - P
do Dr. Quincas.

escarrapachado. Foi empregado

José Ramos Góis Pinto Calsudo - Autor deste modesto
Diteker anćsio João - Diverso. a esta "uma orientação negativa". ${ }^{13}$ Portanto, a leitura que aqui desenvolvo, estando voltada ao "não", intenta a ser na verdade uma desleitura/tresleitura/contraleitura. ${ }^{14}$

\section{A MALÍCIA DA ESCRITA}

A segunda unidade de Serafim Ponte Grande, intitulada "Alpendre”, reúne, de maneira fragmentária, algumas situações vivenciadas pelo protagonista desde a infância até o início da fase adulta. Inicialmente, é enfocada a aquisição da escrita, mas, em vez de uma narrativa sobre as aulas em que Serafim começara a aprender as letras e a formação silábica, há uma exposição de um trecho da cartilha então utilizada por ele (Figura 3). Chama-me a atenção o fato de esse processo de aprendizado ser apresentado como "Primeiro Contato de Serafim e a Malícia”. Por que, no contexto da obra em questão, conhecer a escrita representa conhecer a malícia? De que malícia se trata?

Primeiro Contato de Serafimea Malicia

$$
\mathbf{A}-\mathbf{c}-\mathbf{i}-\mathbf{o}-\mathbf{u}
$$

$\mathrm{Ba}-\mathrm{Be}-\mathrm{Bi}-\mathrm{Bo}-\mathrm{Bu}$

$\mathrm{Ca}-\mathrm{Ce}-\mathrm{Ci}-\mathrm{Co}-\mathrm{Cu}$ 
A palavra "malícia" possui as acepções de "fala, intenção ou interpretação maldosa, picante" e "habilidade para enganar; esperteza, astúcia". ${ }^{15}$ Lembro também o fato de, na linguagem coloquial, essa palavra ser, por vezes, associada ao erotismo e a temas considerados "picantes" do ponto de vista sexual. No âmbito de Serafim Ponte Grande, a escrita é malícia porque subverte ironicamente tanto regras sociais quanto convenções relacionadas à prática literária, as quais dizem respeito, por exemplo, a técnicas de composição e a escolhas temáticas. Cairá no engano aquele que ler tal obra de modo sério e não perceber o tom paródico presente em cada uma de suas linhas, as quais, não raramente, enfocam o comportamento erótico ou sexual dos personagens e rompem com os estereótipos do relacionamento amoroso, como demonstrarei a seguir. Dessa forma, Serafim, ao aprender o bê-a-bá, começa a entrar em contato com a malícia da escrita tornando-se, a partir de então, cada vez mais hábil em redigir textos paródicos.

Tal habilidade pode ser verificada nos trechos do diário pessoal de Serafim ${ }^{16}$ nos quais o protagonista registra o desejo de elaborar um livro: ${ }^{17}$

\section{Têrça-feira}

Ando com vontade de escrever um romance naturalista que está muito em moda. Começaria assim: "Por todo o largo meio disco de praia de Jurujuba, havia uma vida sensual com ares gregos e pagãos. O mar parecia um sátiro contente após o coito".

Nota: Não sei ainda se escreverei a palavra "coito" com todas as letras. $\mathrm{O}$ arcebispo e as famílias podem ficar revoltados. Talvez ponha só a sílaba "coi" seguida de três pontinhos discretos. Como Camões fazia com "bunda". 18

Serafim planeja compor um romance naturalista, gênero em que normalmente a objetividade e a tendência cientificista articulam-se para que seja feita, por meio de uma narrativa tradicional, uma análise da realidade empírica. Embora o protagonista intente afirmar-se como escritor de um gênero que estava na "moda", logo surgem alguns impasses devido à escolha temática e vocabular. Serafim percebe que sua escrita poderá causar revolta na igreja e na família, instituições conservadoras que exercem grande influência na sociedade em geral e na cultura livresca em particular. O termo "coito" detonaria a revolta, já que denota o ato sexual e é considerado obsceno. Para resolver o problema, Serafim, supostamente inspirado em Camões, encontra a alternativa de substituir "coito" por "coi...". Se o grande poeta português teria usado os "três pontinhos discretos" para evitar escrever "bunda" integralmente, Serafim sente-se autorizado a fazer o mesmo com "coito". É, contudo, bastante duvidosa a afirmação de que se encontra algum "bun..." na lírica camoniana. Ademais, 
a comparação com Camões, um dos principais nomes da literatura em língua portuguesa, não deixa de soar pretensiosa.

Não à toa, há, nas primeiras linhas do romance naturalista de Serafim, referência à figura mitológica "sátiro", palavra que tem a mesma origem de "sátira". Nos comentários de Serafim sobre o livro que planeja escrever, transparece um irônico e debochado tratamento da produção e da recepção da literatura: os escritores procuram seguir a "moda" e baseiam-se em nomes consagrados - como Camões -, enquanto os leitores rechaçam obras que ferem as regras do decoro. A sátira continua no seguinte trecho do diário de Serafim:

\section{Têrca-feira}

$[\ldots]$

Volto de nôvo a preocupar-me com o romance que imaginei escrever e que acho que sairá com pecedônimo. Tenho alguns apontamentos tomados sôbre o tipo principal, a jovem Marquesa de M... Quando o sedutor, o invencível galã Álvaro Velasco, inicia a sua ofensiva por debaixo da mesa de jantar, ela retira bruscamente o pèzinho. Nota humorística: a Marquesa tem um calo. ${ }^{19}$

Segundo Campos, “o barbarismo 'pecedônimo’ é um ingrediente óbvio da sátira”. ${ }^{20}$ Ademais, a opção de assinar o romance com um falso nome corrobora a ideia de que Serafim é hábil em enganar por meio da escrita. Nesse caso, como o engano recai sobre a identidade do autor do livro, ocorre o que Süssekind denomina "desfiguração autoral" ${ }^{21}$ Outro aspecto relevante no excerto acima é a caracterização dos protagonistas do romance de Serafim: a Marquesa de M... é "jovem" e forma par com Álvaro Velasco, um "sedutor" e "invencível galã”. Os adjetivos pomposos remetem a livros que tematizam intrigas amorosas, aventurescas e cheias de clichês melodramáticos. O diminutivo "pèzinho" ajuda a conferir à Marquesa um aspecto delicado e apaixonante. Todavia, a "nota humorística" quebra as expectativas criadas a princípio, uma vez que rompe com a imagem idealizada da mulher amada, ao informar que a Marquesa possui um calo no pé.

Registros no diário de Serafim explicitam que o protagonista esforça-se para seguir a "moda" literária então em voga e para se tornar um exímio escritor: conhece, por meio do amigo Celestino Manso, a "questão da impersonalidade em arte" e os "detalhes do escabroso caso Victor Hugo-Sainte Beuve";22 traça para si "um sério programa de estudos"; ${ }^{23}$ enfrenta as queixas da esposa, Lalá, que o acusa de gastar muita energia elétrica com as leituras; ${ }^{24}$ preocupa-se em deixar a escrita em dia; ${ }^{25}$ convive com literatos e intelectuais. ${ }^{26}$ Para escrever seu romance naturalista, Serafim até compra "a prestações uma caneta-tinteiro", porém ela "não funciona muito bem". ${ }^{27}$ Entretanto, todo esse esforço gera um efeito diferente do 
previsto, pois Serafim não segue à risca o protótipo da figura do homem das letras. A caneta-tinteiro pode ser compreendida, portanto, como uma metonímia do desajuste do próprio Serafim, escritor que, embora tente, não se adéqua muito bem aos preceitos da cultura livresca na qual está inserido.

O contraponto de Serafim é Pires de Melo, "o grande literato que passou a vida debruçado sôbre a alma feminina". Dorotéia, uma das amantes de Serafim, é caracterizada por Pires como "Tão loira que parece volatizar-se na manhã loira!", ${ }^{29}$ frase que demonstra que tal personagem é o protótipo do escritor eloquente, vazio e afeiçoado aos lugares-comuns. Já Serafim, ao esboçar um romance, parodia o tratamento usual dos temas amorosos e recorre a elementos sensuais e/ou humorísticos que dessacralizam a tradição livresca. Todavia, a escrita de Serafim é enganosa, pois, se, por um lado, ele cria para si a imagem de um literato convencional semelhante a Pires, ${ }^{30}$ por outro, as notas sobre o romance revelam o quão subversivo é o protagonista. Portanto, a malícia da escrita de Serafim sustenta-se nessa ambiguidade. Trata-se de uma escrita que parece ser convencional e séria, enquanto, na verdade, não o é. Tal como a caneta-tinteiro que "não funciona muito bem, mas serve", ${ }^{31}$ o escritor Serafim serve para algo - serve para parodiar práticas e modelos literários.

O romance naturalista que Serafim planejava escrever é mencionado apenas nos excertos do diário presentes na terceira unidade de Serafim Ponte Grande, intitulada "Folhinha conjugal ou seja Serafim no front". Nesses excertos, não é informado se a obra de Serafim chegou a ser concluída. Permanece, pois, uma incógnita o resultado do projeto esboçado no diário. Entretanto, pode-se dizer que os ideais que guiam esse projeto encontram-se concretizados em "O Merediano de Greenwich", o "romance de capa e pistola" que compõe a sétima unidade de Serafim Ponte Grande. Como passo a demonstrar, em "O Merediano de Greenwich" também se verifica a malícia de uma escrita paródica.

\section{A PARÓDIA NA PARÓDIA}

Se o romance naturalista de Serafim foi apenas esboçado, "O Merediano de Greenwich" apresenta-se como um todo acabado, ainda que de pequena extensão. Trata-se de uma obra que é composta por cinco capítulos e que possui até mesmo epígrafe e capa completa (Figura 4). Aqui, à semelhança do que Serafim planejara fazer em seu romance, enfocam-se as investidas amorosas de um experiente conquistador - Serafim, que então se apresenta como Barão - sobre uma mulher fascinante - Dona Solanja. A história se passa a bordo de um transatlântico e à beira do cais de Nápoles, num ambiente em que, retomando as palavras de Serafim, "havia uma vida sensual", de modo que "o mar parecia um sátiro contente após o coito". ${ }^{32}$ 
BIBLIOTECA DA JUVENTUDE

O Merediano de

Greenwich

ROMANCE DE CAPA E PISTOLA

EM 4 PARTES E 1 DESENLACE

"Andando mas mas se sabe".

Cristoväo Colombo e outros

comissários de bordo
As características acima destacadas apontam para o fato de que "O Merediano de Greenwich", ao ser inserido em Serafim Ponte Grande, desempenha um importante papel na realização daquilo que Süssekind identifica como desmontagem da forma-livro. ${ }^{33} \mathrm{~A}$ exposição da capa - com a indicação do gênero e do plano da obra ("romance de capa e pistola em 4 partes e 1 desenlace"), bem como com a vinculação desta à "Biblioteca da Juventude" 34 - tensiona a forma-livro no âmbito material. Já a linguagem empregada, a caracterização dos personagens, a abordagem do relacionamento amoroso e o fechamento da história são responsáveis por contestar, no âmbito textual, os modelos literários. A contestação textual inicia-se com as palavras impressas na capa: além do paródico nome da editora ou coleção "Biblioteca da Juventude", há uma "substituição maliciosa" 35 de "espada" por "pistola", substituição essa decorrente de releitura crítica dos romances românticos. A narrativa sobre o relacionamento entre o Barão Serafim e a Dona Lalá confirmará que "O Merediano de Greenwich" parodia a tradição romanesca. Segundo afirma Campos:

Como nos romances de "capa-e-espada", nos romances "românticos”, a efusão amorosa acaba em tragédia (no caso, porém, em tragicomédia, com uma fuzilaria "fálica" e um linchamento humorístico). Ainda como nesses romances, a intervenção de uma nova personagem "justiçadora" (que se revela uma antiga "vítima" das aventuras serafínicas, a Dorotéia do "Terremoto Doroteu") provoca o descabelado desenlace. ${ }^{36}$ 
Em um primeiro nível de análise, verifica-se que "O Merediano de Greenwich" incorpora alguns elementos característicos dos romances tradicionais, tais como: personagen estereotipados; abordagem de um amor intenso e idealizado; final trágico; e estrutura narrativa linear, a qual segue a ordem cronológica dos acontecimentos (a situação em que Serafim e Solanja se conhecem, as técnicas de conquista empregadas pelo "galâ", as recusas da "mocinha", a primeira vez em que esta cede às investidas e, por fim, o desenlace da história). Soma-se a isso o emprego de uma linguagem empolada, perceptível nos "tratamentos cerimoniosos e afetados $^{\prime \prime 37}$ entre o senhor Barão e a madama Solanja, bem como no "espírito enfático-sentimental" ${ }^{38}$ dos títulos dos capítulos (I - A viva morta!; II - A mascarada flutuante; III - A sombra retrospectiva; IV - Vendetta!! e V - Epílogo final).

Uma análise mais atenta revelará, contudo, que todos esses elementos convencionais são incorporados de modo paródico. Os personagens apresentam traços estereotipados, ao mesmo tempo que tomam atitudes que desconstroem esses traços, como evidencia a passagem em que Serafim fez um gesto incoerente com o contexto de sedução em que ele e Solanja se encontravam: "Serafim tossiu, escarrou ligeiramente, passou o pé por cima, enxugou os bigodes e prosseguiu". ${ }^{39}$ $O$ fato de o Barão ter escarrado não deixa de conferir um tom humorístico à cena, cujo romantismo é, assim, quebrado.
Ademais, se alguns trechos idealizam Dona Solanja - "uma mulher nova e bela, mais que bela, duma severa beleza"; "revelara-se de uma finíssima intelectualidade" ${ }^{41}$-, outros a retiram do pedestal e demonstram que ela tem comportamentos incompatíveis com os de uma "mocinha" - "Só quero lavar as mãos e mijar!"; 42 "Tenho medo que me dê gases!";3 "a jovem dama passou ràpidamente a mão nas calças do atarantado Serafim e tirando-lhe a pistola, sem hesitar, sapecou seis vêzes azeitonas no coração da desgraçada Dorotéia". ${ }^{44}$

Os excertos reunidos no parágrafo anterior demonstram que a linguagem de "O Merediano de Greenwich" também é dúbia, na medida em que combina os clichês de um estilo supostamente elevado com construções coloquiais. Juntamente com a mistura de registros, misturam-se temas elevados e corriqueiros. Além disso, o desenlace da narrativa articula a tragicidade comum às histórias sobre amores impossíveis e a comicidade de um fuzilamento e de um linchamento inesperados. Quando começava a se delinear um final feliz para Solanja e Serafim, os quais caminhavam de braços dados pelo cais de Nápoles, irrompe "uma mullher mal vestida e cheirando a alho, com uma garrucha no polegar" ${ }^{45} \mathrm{~A}$ mulher é a antiga amante de Serafim, Dorotéia, que dispara "três estampidos na direção do feliz casal". ${ }^{46}$ Serafim e Solanja não são atingidos, e esta acaba por atirar, com a pistola de seu acompanhante, em Dorotéia. No "Epílogo final” - expressão 
pleonástica que "acentua a burleta" ${ }^{\text {"7 }}$-, uma única frase informa: "Dona Solanja foi linchada pelas senhoras da multidão" ${ }^{48}$

A classificação de "O Merediano de Greenwich" como um "romance de capa e pistola" é corroborada pelo desenlace da narrativa, no qual Solanja utiliza a pistola de Serafim para matar Dorotéia. Mas a substituição de "espada" por "pistola" não se deve apenas a esse dado do enredo. Como mencionei acima, a escolha da expressão "capa e pistola" é uma maneira de explicitar que "O Merediano de Greenwich" retoma o "romance de capa e espada" de modo paródico e, ao fazê-lo, dessacraliza os formatos literários convencionais. É possível compreender tal obra como um não-livro, pois ela se apresenta como um livro dotado inclusive de capa, ao mesmo tempo que se nega enquanto um livro. Como salienta Süssekind, por meio dos não-livros "se investigam as propriedades do livro e da experiência literária". ${ }^{49}$ Isso significa que as versões livrescas em negativo não deixam de "interagir com os padrões do livro convencional". ${ }^{50}$

O paródico "O Merediano de Greenwich" pode ser entendido como uma espécie de mise en abyme de Serafim Ponte Grande, já que, como este, problematiza a prática literária. A malícia que sustenta a escrita de Serafim Ponte Grande é reproduzida, em pequena escala, em "O Merediano de Greenwich". Esse jogo especular entre a obra oswaldiana e as unidades que a compõem chega a ser delineado nas referências ao romance naturalista que Serafim planejara a escrever. Contudo, o espelhamento se consolida de fato somente com "O Merediano de Greenwich".

\section{O FIM DE SERAFIM}

Escrever com malícia. Ser um livro que parodia a si mesmo. Tornar-se um não-livro. Assim podem ser sintetizadas as principais finalidades de Serafim Ponte Grande, obra cuja "inspiração inteira terá nascido de uma situação crítica".$^{51}$ Como argumenta Butor, a literatura realiza uma crítica da própria literatura quando o escritor, sensível às brechas deixadas pelos escritores que o precederam, assume um trabalho de reescritura e estabelece novos modelos, os quais "denunciarão, no conjunto romanesco ao qual eles se oporão necessariamente, apesar de toda a sua prudência e de toda a sua esperteza, aquilo que nele havia de mentiroso" ${ }^{52}$ Devido à situação crítica, "a fórmula do romance atual é pois simplesmente uma forma de paródia". ${ }^{53}$ Por meio da paródia, desconstroem-se práticas literárias, desconstrução essa que em Serafim Ponte Grande, como demonstrei acima, ocorre material e textualmente. Em relação a tal aspecto, é importante destacar que o gesto de produzir um romance paródico encontra um reflexo tanto no projeto de escrita registrado por Serafim em seu diário quanto em "O Merediano de Greenwich". Portanto, "no interior da obra se instaura não uma obra de arte imaginária, mas todo um sistema de refrações". ${ }^{54}$ 
Ademais, a incorporação do diário de Serafim e do "romance de capa e pistola" evidencia que Serafim Ponte Grande compõe-se por uma série de fragmentos de origem diversa e que, por conseguinte, rompe com os ideais de linearidade, legibilidade e finitude, os quais são atribuídos ao objeto livro. Na esteira de Butor, trata-se de uma obra móbile que exige a atividade do leitor, uma vez que comporta várias possibilidades interpretativas. ${ }^{55}$ Diante do inacabamento da obra literária, o crítico vê-se no desafio de fazer com que sua invenção consiga "prolongar a do autor" ${ }^{56}$ No caso do presente trabalho, minha investigação crítica teve como fim continuar, desdobrar a negatividade de Serafim Ponte Grande, de modo a explicitar elementos que fazem desta produção oswaldiana um não-livro.

\section{REFERÊNCIAS}

ANDRADE, Oswald de. Serafim Ponte Grande. In: ANDRADE,

Oswald de. Obras completas. Rio de Janeiro: Civilização Brasileira, 1972 v. 2

BUTOR, Michel. Crítica e invenção. In: BUTOR, Michel. Repertório. Tradução de Leyla Perrone-Moisés. São Paulo: Perspectiva, 1974. p. 191-203.

CAMPOS, Haroldo de Serafim: um grande não-livro. In: ANDRADE, Oswald de. Obras completas. Rio de Janeiro: Civilização Brasileira, 1972. v. 2, p. 99-127.
CANDIDO, Antonio. Estouro e libertação. In: CANDIDO, Antonio. Varios escritos São Paulo: Livraria Duas Cidades, 1977a. p. 33-

CANDIDO, Antonio. Digressão sentimental sobre Oswald de Andrade. In: CANDIDO, Antonio. Vários escritos. São Paulo: Livraria Duas Cidades, 1977b. p. 57-87.

MALÍCIA. In: HOUAISS, Antônio; VILLAR, Mauro de Salles.

Minidicionário Houaiss da língua portuguesa. Rio de Janeiro: Objetiva, 2009. p. 481

MELOT, Michel. Livro,. Tradução Marisa Midori Deaecto, Valéria Guimarães. Cotia: Ateliê Editorial, 2012.

SUSSSEKIND, Flora. Não-livros. In: SÜSSEKIND, Flora; DIAS,

Tania. A historiografia literária e as técnicas de escrita. Rio de Janeiro: Casa de Rui Barbosa: Vieira e Lent, 2004. p. 442-488.

\section{NOTAS}

BUTOR. Crítica e invenção.

2 BUTOR. Crítica e invenção, p. 200

3 CANDIDO. Estouro e libertação, p. 37.

4 CAMPOS. Serafim: um grande não-livro, p. 107.

5 As onze unidades que compõem Serafim Ponte Grande são: "Recitativo"; "Alpendre"; "Folhinha conjugal ou seja Serafim no front" "Testamento de um legalista de fraque"; "No elemento sedativo"; "Cérebro, coração e pavio"; "O Merediano de Greenwich"; "Os esplendores do Oriente"; "Fim de Serafim; "Errata"; "Os antropófagos". 
6 Nessa obra tradicionalmente classificada como um romance, o leitor encontra gêneros textuais diversos, a saber: poema, peça teatral, diário, noticiário, abaixo-assinado, dicionário de nomes, carta convocação judicial, interrogatório, relato de sonho, anúncio, ensaio, testamento, receita, errata e até mesmo um romance.

7 Em "Estouro e libertação", Candido, ao caracterizar a ficção oswaldiana, argumenta que Serafim Ponte Grande, juntamente com cão" (CA sentimentais de João Mriamar, forma a lase da negação" (CANDIDO. Estouro e libertação p. 45). Apesar de atestar negatividade de Serafim Ponte Grande, Candido năo explora tal aspecto tanto quanto Campos e chega a dizer que tal romance é faho, como se Oswald de Andrade tivesse caldo em un comodismo

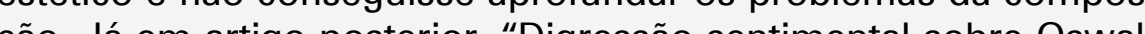
ção. Já em artigo posterior, "Digressão sentimental sobre Oswald de Andrade", Candido revê seu posicionamento e concorda com a análise proposta por Campos. Mas, mesmo nesse artigo posterior, transparecem a afirmação e a valorização do livro, em detrimento do náo-livro, como evidencia a seguinte passagem: "Aceito o reparo de Haroldo de Campos [...] e reconsidero o meu juízo. A leitura de Serafim náo permite dizer que e inferior a Miramar ou, como me parecia, um 'fragmento de grande livro'. É um grande livro em toda a sua força, mais radical do que Miramar [...]" (CANDIDO. Digressão sentimental sobre Oswald de Andrade, p. 84).

8 Em Livro, Michel Melot reflete sobre o fato de o livro ser um objeto que materializa um conjunto de valores tradicionalmente prezados pela cultura ocidental e que, por conseguinte, se tornou tão valorizado entre nós. Segundo Melot, para se compreender o poder assumido pelo livro, é necessário voltar-se à forma elementar do objeto, isto é, à sua dobra, a qual, longe de ser algo natural, foi meticulosamente estudada, a fim de se alcançar uma geometria rigorosa e simétrica. A dobra organiza as folhas, de modo que a superfície se transforma em um volume a ser manuseado, folheado, desde o início até o fim. Já a capa, como uma armadura e couraça, circunscreve o livro, protegendo-o das intempéries, mas sobretudo fixando-o em um espaço definitivo. Melot destaca duas consequo promessas dessa geometria: 1) o significado do livro é reconhecido por seu autor, ou seja, a mensagem é previamente dominada por quem a publica; 2) o significado do livro, uma vez que se conclui a dobra, é esgotado e será esclarecido no final das páginas. Portanto, a unidade física estaria articulada a uma unidade de sentido e a uma totalidade.

SÜSSEKIND. Não-livros, p. 459

10 CAMPOS. Serafim: um grande não-livro, p. 102.

SÜSSEKIND. Não-livros, p. 458-459.

12 Manterei a ortografia da edição de Serafim Ponte Grande por mim consultada.

13 SÜSSEKIND. Não-livros, p. 488.

14 SÜSSEKIND. Não-livros, p. 458.

15 HOUAISS. Minidicionário Houaiss da língua portuguesa, p. 481.

${ }_{16}$ O diário pessoal de Serafim compõe, juntamente com "O Terremoto Doroteu" - um apêndice do diário (CAMPOS. Serafim: um grande não-livro, p. 110) -, a terceira unidade de Serafim Ponte Grande, a qual se intitula "Folhinha conjugal ou seja Serafim no front".

17 A malícia da escrita de Serafim pode ser igualmente verificada nos poemas compostos pelo protagonista e inseridos ao longo da obra Serafim Ponte Grande. Contudo, a análise de tais poemas foge aos objetivos do presente trabalho, o qual se dedica especialmente ao gênero romance.

18 ANDRADE. Serafim Ponte Grande, p.149-150.

19 ANDRADE. Serafim Ponte Grande, p. 152.

CAMPOS. Serafim: um grande não-livro, p. 110.

21 SÜSSEKIND. Não-livros, p. 466

ANDRADE. Serafim Ponte Grande, p. 151

23 ANDRADE. Serafim Ponte Grande, p. 154

24 ANDRADE. Serafim Ponte Grande, p. 155. 
25 ANDRADE. Serafim Ponte Grande, p. 156.

26 ANDRADE. Serafim Ponte Grande, p. 151-161.

27 ANDRADE. Serafim Ponte Grande, p. 156.

28 ANDRADE. Serafim Ponte Grande, p. 160.

29 ANDRADE. Serafim Ponte Grande, p. 160.

30 Serafim inclusive expressa em seu diário a admiração que sentia pela obra de Pires, como exemplifica a seguinte passagem: "Saio à noite e procuro o Pires de Melo que lê-me pela terceira vez a sua encantadora novela Recordação de um Ósculo" (ANDRADE. Serafim Ponte Grande, p. 161).

31 ANDRADE. Serafim Ponte Grande, p. 156.

32 ANDRADE. Serafim Ponte Grande, p. 149.

33 SÜSSEKIND. Não-livros, p. 468.

34 ANDRADE. Serafim Ponte Grande, p. 223.

35 CAMPOS. Serafim: um grande não-livro, p. 116, grifo meu.

36 CAMPOS. Serafim: um grande não-livro, p. 116

CAMPOS. Serafim: um grande não-livro, p. 116.

38 CAMPOS. Serafim: um grande não-livro, p. 116

39 ANDRADE. Serafim Ponte Grande, p. 227.

40 ANDRADE. Serafim Ponte Grande, p. 226.

41 ANDRADE. Serafim Ponte Grande, p. 227.

42 ANDRADE. Serafim Ponte Grande, p. 230.

43 ANDRADE. Serafim Ponte Grande, p. 230.

44 ANDRADE. Serafim Ponte Grande, p. 231.

45 ANDRADE. Serafim Ponte Grande, p. 231.

46 ANDRADE. Serafim Ponte Grande, p. 213.

47 CAMPOS. Serafim: um grande não-livro, p. 116.
48 ANDRADE. Serafim Ponte Grande, p. 231.

SÜSSEKIND. Não-livros, p. 452

50 SÜSSEKIND. Não-livros, p. 488

BUTOR. Crítica e invenção, p. 194

52 BUTOR. Crítica e invenção, p. 194.

53 BUTOR. Crítica e invenção, p. 193.

54 BUTOR. Crítica e invenção, p. 201, grifo do autor

5 BUTOR. Crítica e invenção, p. 203.

BUTOR Crítica e invenção, p. 199 